\title{
MODERN APPROACHES TO PERFORMANCE OF TOXICOLOGICAL AND HYGIENIC STUDIES OF WELDING FUMES (REVIEW)
}

\author{
A.O. LUKIANENKO ${ }^{1}$ and A.V. DEMETSKAYA ${ }^{2}$ \\ ${ }^{1}$ E.O. Paton Electric Welding Institute, NASU \\ 11 Kazimir Malevich Str., 03680, Kiev, Ukraine. E-mail: office@paton.kiev.ua \\ ${ }^{2}$ Institute of Occupational Medicine, NAMSU \\ 75 Saksagansky Str., 01033, Kiev, Ukraine
}

\begin{abstract}
The paper provides an overview of the results of studying the nanoscale fractions in the working zone air during welding operations and in the welder's breathing zone, as well as data of toxicological studies of welding fumes (WF) in experiments on laboratory animals (in vivo) and in cell culture experiments (in vitro). It is suggested that the high disease rate in welders can be caused not only by toxicity of WF components having irritating and mutagenic effects, but also by the ability of nanoscale particles (nanoparticles) to penetrate deeply into the tissues. The data of hygienic studies of nanoparticle emission into the working zone air during welding operations, as well as of studying nanoscale fraction deposition in the respiratory tract of welders are presented. It is shown that decrease in the content of hexavalent chromium and manganese in the welding consumable involves increasing the concentrations of other metals, and thus does not guarantee safety for the welder. The role of prediction of WF harmful effects on the body by controlling the working conditions using modern hygienic approaches is substantiated. Simultaneous application of in vitro and in vivo methods to provide the most complete information about the potential hazards of WF, peculiarities of biological action of its components, as well as the need to develop not only informative, but also less time-consuming and costly express-methods of screening assessment of toxicity of WF, generated at different types of welding was substantiated. These methods will allow evaluation of the cumulative effect of the impact of totality of toxicants present in WF solid component, including unidentified components. 21 Ref.
\end{abstract}

Keywords: welding fumes, solid component of welding fume, working zone air, cytotoxicity, in vitro, in vivo, nanoparticles

Members of welding professions have a special place among the workers exposed to a set of harmful factors. This is due to broad application of welding technologies and operations in different industries, construction, transportation, etc. [1] with the number of welders is increasing steadily. While in 2008 their number was more than 1 mln persons, in 2010 already there were reports about $5 \mathrm{mln}$ welders worldwide [2] that may be associated with increase in population and development of infrastructure.

Depending on the type of production operation, kind of metal, type of welding consumables and production technologies, the welder is exposed to harmful production factors of different nature. Investigations of presence of harmful substances in the air of working zone and breathing zone of workers, engaged in various types and processes of welding, showed that the most unfavourable factor is exactly the chemical one. Performance of welding operations is accompanied by formation of harmful factors of chemical nature, which are based on toxic components of welding fumes (WF), as weld as flux dust. In its turn, their

(c) A.O. LUKIANENKO and A.V. DEMETSKAYA, 2016 quantitative and qualitative composition depends on welding process, metal composition, etc. [3].

Note that among the set of harmful industrial factors WF, in the opinion of many researchers, have the most negative influence on the human body. Biological activity of metal compounds, present in WF composition, depends on their ability to bind with blood and tissues proteins, increase the permeability of cell membranes or damage them, block intercellular and extracellular enzyme systems that, eventually, leads to pathological changes in the body. Results of analysis of electric welders' incidence rates revealed that the nervous, respiratory and osteomuscular systems are the most sensitive to the impact of the specific set of harmful factors [4]. Clinical and epidemiological studies confirm the association of pulmonological effects with higher rate of cardio-vascular disorders, and the results of recent in vivo toxicological studies on laboratory animals confirmed the hypothesis of direct damaging effect of WF on cardio-vascular system [5].

It is known that the level of risk of WF having a harmful effect on the body is, primarily, determined by welding process and type of welding equipment, technological parameters of welding modes (welding 
current, arc voltage, electrode diameter), kind and composition of welding consumable. The nature and severity of welders' diseases caused by WF harmful substances depend on their concentration in the breathing zone. Concentration of WF solid component (WFSC) and other harmful substances in welders' breathing zone grows in proportion to their formation rate in the arc zone [1].

Despite the fact that WFs have been studied for quite a long time, many aspects of the dependence of their biological aggressiveness on the main physico-chemical properties are still unclear. The latter include dispersity of particles of WFSC, their structural parameters, and solubility of individual components. At present it has been suggested that the high incidence rate in electric welders is due not only to toxicity of WF components, characterized by irritating and mutagenous action, but also by ability of nanoscale particles (nanoparticles) to penetrate deeply into the tissues. It is known that sufficient experimental data has been accumulated in recent years, which indicate that the substances in the nanorange are characterized by higher bioactivity and damaging effect $[6,7]$.

In particular, results of conducted morphological and chemical studies are indicative of the same nature and similar mechanisms of WFSC formation in welding with electrodes with different types of coatings. Nanosized particles are the main components of all WFSC. They are mainly grouped into agglomerates, numbering from a few up to thousands of particles, which, according to X-ray microanalysis, consist predominantly of compounds of alkali metals, silicates and iron oxides. Integral chemical composition of WFSC nanosized particles essentially depends on the type of electrode coating. It is established that minimum dimensions of WFSC stable components are quite close (300-600 nm) in the studied welding electrodes (UONI 13/45 and 2TsM7) [8]. However, their characteristics of solubility in aqueous medium and stability to mechanical impact significantly differ.

This circumstance is extremely important in terms of potentially dangerous interaction of WF with the human body and necessitates investigations of WFSC nanosized fractions in the welder's breathing zone. In the European countries and the USA studies of nanosized particle deposition in the respiratory tract of members of welding professions are performed using personal samplers [9]. When studying the deposition of nanosized fractions of chromium, manganese and nickel in the respiratory tract in gas-shielded metal-arc welding of low-carbon and stainless steel and in flux-cored wire arc welding of low-carbon steel, the welders were equipped with individual samplers of WF nanofractions, as well as cassette filters for evaluation of the total number of particles. Concentration of manganese for both the welding processes varied in the range of 2.8-199, nickel - 10-51, chromium - 40-105 mg/m $/ \mathrm{m}^{3}$. Concentration of hexavalent chromium varied in the range of $0.5-1.3 \mathrm{mg} / \mathrm{m}^{3}$ [9]. As regards the fraction of manganese, chromium and nickel in particles of nanosized fractions relative to their content in WF, it is as follows: in welding of low-carbon steel manganese fraction was equal to $10-56 \%$, and in welding of stainless steel manganese fraction was 59, that of nickel was 64 and that of chromium was $90 \%$. These results are indicative of the fact that the vast majority of chromium, manganese and nickel are present in particles of nanosized fractions smaller than $300 \mathrm{~nm}$ [9].

Nanoparticle emissions in working zone air during welding operations can be assessed also using stationary instruments, which record in real time the total number of particles from 1 up to $200 \mathrm{~nm}$ and their size distribution. In particular, diffusion aerosol spectrometer DAS-2702 was used to obtain data on dynamics of changes in time of the number of WFSC particles in different ranges of their dimensions from 1 up to $100 \mathrm{~nm}$, after welding with electrodes with rutile and carbonate-fluorite type of coating. It was found that nanoparticle concentration in working zone air depends on welding electrode grade and diameter, as well as distance from the welding zone (particle concentration decreases with greater distance from the sampling point to the welding zone). It was also established that in the production premises where welding operations are performed all the time, WF nanoparticles can stay in the air medium for a long time after the operations are stopped [10].

Kind of welding consumable, particle size and time after impact are important factors in formation of free radicals and deposition of particles, which should be taken into account when developing protection strategies [2]. Animal studies showed that WF is removed from the body in three stages. At the first stage, alveoli and airways are cleared with the help of mucus, which then penetrates into the alimentary tract and is quickly removed with semi-clearance period of one day. At the second stage, the process runs slower, semi-clearance period is up to 7 days. At the third clearance stage, clearance of the lungs proceeds slower and is more complex: semi-clearance period can be up to several weeks. At this stage, removal of individual particles is associated with their ability to dissolve in tissues and with continuous clearance of the lungs by macrophages [11].

It is remarkable that in vivo experiment to study long-term presence and deposition of metals in the lungs, as well as inflammatory potential after inhalation 
priming of laboratory animals (rats) with WF, metals detected in the lungs were removed at different times. Priming was performed with WF (57 \% Fe, $20 \%$ Cr, $14 \% \mathrm{Mn}, 9 \% \mathrm{Ni}$ ), which forms in stainless steel welding and WF (83 \% Fe, $15 \% \mathrm{Mn}$ ), which forms in low-carbon steel welding. So, potentially more toxic chromium and manganese were removed from the lugs faster than iron, probably, owing to their movement from the respiratory tract to other tissues [12].

It should be noted that the consequence of welding processes, generating aerosols containing such toxic metals as hexavalent chromium, manganese and nick$\mathrm{el}$, is lung tissue damage and inflammation and lung tumors in animal experiments. Manganese presence in WF increases the risk of undesirable neurological responses, such as Parkinson disease, etc. [13]. There are data on manganese nanoparticle involvement in development of manganese-induced Parkinsonism in welders, because of its ability to penetrate into the brain through olfactory nerve [7]. In its turn, chromium and nickel presence can cause damage and inflammatory processes in the lungs, tumors, immune disorders and systemic toxicity. Nickel can cause malignant neoplasms in the lungs [13]. Despite the fact that in the USA the permissible exposure limit in the workplace was lowered (from 0.05 to $0.005 \mathrm{mg} / \mathrm{m}^{3}$, that, by the way, is 2 times lower than in Ukraine), in practice it is not always possible to protect welders who often have to work in closed confined space, and exhaust ventilation can be ineffective here [13]. It is known [13] that this gave rise to the initiative of minimizing potentially hazardous components in welding consumables through development of new consumables with lower Cr (VI) and Mn content.

WF potential hazards are traditionally assessed using both toxicological methods in vivo (on laboratory animals), and adequate short-term tests in vitro (when experiments are performed «in vitro» — outside the living organism). Express-methods in vitro allow determination of WF toxicity in a relatively short time, thus saving time and reducing the number of laboratory animals used in experiment. However, these methods are not mutually exclusive. Express-methods in vitro are required for screening assessment of WF toxicity, providing preliminary information on potential hazard of a welding consumable and maximum rational planning of experimental studies during in vivo tests.

Specifics of biological impact of WF containing different quantities of manganese, iron, chromium, nickel and silicon in WFSC, were précised earlier. The connection of WF cytotoxic effect with WFSC initial composition, their solubility in biological solutions of the body, and biosphere simulator solution was established. The extent and nature of WFSC combined impact are enhanced at increase of the content of potassium, silicon, fluorine, sodium and calcium (in decreasing order of harmful effect) [14]. In vitro studies of cell culture showed that soluble particles, formed in manual arc welding of stainless steel, are more toxic than WF particles, forming in gas-shielded arc welding of stainless and low-carbon steel [15].

The role of WFSC soluble and insoluble components containing hexavalent chromium [16-20] was also studied. In particular, it was established that WFSC forming in coated electrode manual arc welding is more toxic, and has a transforming effect on laboratory animal cells, that was associated with the presence of hexavalent chromium in WFSC, while the contribution of other components, namely trivalent chromium, fluorides, nickel and manganese is small. Insoluble components containing hexavalent chromium have a more toxic and transforming effect on fibroblasts of hamster kidneys than hexavalent chromium.

Here mitotic delay cannot be attributed only to hexavalent chromium concentration, it can be also affected by other components of WFSC [20].

Now it seems clear that a combination of in vitro and in vivo methods provides the most complete information not only about WF potential hazard, but also about the specifics of biological effects of its components. In particular, assessment of pulmonary toxicity of fumes formed by $\mathrm{Ni}-\mathrm{Cu}$-containing electrodes (Ni-Cu WF) used as substitutes in $\mathrm{Ar}$ and $\mathrm{CO}_{2}$ welding of stainless steel in experiments in vitro (culture of rat pulmonary macrophages in the doze of 0.05 and $0.25 \mathrm{mg} / \mathrm{ml}$ ) and in vivo (intratracheal and intraperitoneal priming of laboratory animals in the dozes of 0.5 and $2 \mathrm{mg}$ per rat demonstrated persistent damage and inflammation of lung tissue, as well as direct damaging action of pulmonary macrophages. Despite the fact that all the three aerosols ( $\mathrm{Ni}-\mathrm{Cu} \mathrm{WF}$, as well as aerosols, formed in stainless and low-carbon steel welding) reduced macrophage viability in the high dose $(0.25 \mathrm{mg} / \mathrm{ml})$ and had no significant effect in the low dose $(0.05 \mathrm{mg} / \mathrm{l})$, after $24 \mathrm{~h} \mathrm{Ni-Cu} \mathrm{WF}$ caused macrophage death in the low dose $(0.05 \mathrm{mg} / \mathrm{ml})$, i.e. demonstrated higher cytotoxicity compared to fumes generated in welding stainless and low-carbon steel. Thus, despite chromium reduction, considerable levels of nickel, copper and other potentially hazardous metals (titanium, aluminium) can enhance WF cytotoxic action [13].

Similar results were obtained when studying cytotoxic effects of Ni- and Cu-based welding consumable and two well-studied WF, formed in gas-shielded arc welding of stainless and low-carbon steel [21]. While WF formed in stainless and low-carbon steel 
welding lead to increased production of free radicals, compared to $\mathrm{Ni}-\mathrm{Cu}$-containing material, the fumes from this new consumable were more toxic, including cell death and causing mytochondrial dysfunction in low doses $(0.05 \mathrm{mg} / \mathrm{ml})$.

Thus, despite the fact that toxic cell reactions in response to WF effect largely depend on metal composition, recent results of in vitro and in vivo studies convincingly show that reduction of hexavalent chromium and manganese content in welding consumable implies higher concentration of other metals, and, therefore, does not guarantee welder's safety.

In conclusion, it should be noted that prediction of harmful effects on the body by controlling the working conditions with application of modern hygienic approaches, and a complex approach to performance of toxicological studies of welding consumables (including new, potentially less toxic ones) in vivo and in vitro experiments have an important role in the search of effective methods of prevention of WF toxic component formation, and, accordingly, prevention of professional diseases. It is of certain interest to develop not only informative, but also less labour-consuming and expensive express-methods of screening assessment of toxicity of WF formed in different welding processes that will allow evaluation of cumulative effect from the impact of the totality of toxicants present in WFSC, including unidentified components. In its turn, substantiated and rational application of modern methods of WF toxicological-hygienic studies will contribute to a deeper understanding of processes, proceeding in the air of working zone in welding, and in biological media, as well as development of safer welding consumables and minimizing professional risk for welding profession members, respectively.

1. Levchenko, O.G. (2010) Occupational safety in welding productionn: Tutorial. Kyiv: Osnova.

2. Leonard, S.S., Chen, B.T., Stone, S.G. et al. (2010) Comparison of stainless and mild steel welding fumes in generation of reactive oxygen species. Part Fibre Toxicol., Nov. 3.

3. Gorban, L.M., Timoshina, D.P. (2004) Factors of professional risk of workers of modern welding production and ways for optimizing of their labor conditions. In: Proc. of $24^{\text {th }}$ Congress of Hygienists of Ukraine on Hygienic Sci. and Practice at the Boundary of Centuries, Vol. 2, 69-71.

4. Kusraeva, Z.S. (2011) Assessment of professional risk in modern methods of electric arc welding and cutting of metals: Syn. of Thesis for Cand. of Medical Sci. Degree. St.-Petersburg.

5. Zheng, W., Antonini, J.M., Lin, Y.C. et al. (2015) Cardiovascular effects in rats after intratracheal instillation of metal welding particles. Inhal Toxicol., 27(1), 45-53.
6. Oberdoerster, G. (2010) Safety assessment for nanotechnology and nanomedicine: Concepts of nanotoxicology. $J$. Int. Med., 267(1), 89-105.

7. Elder, A., Gelein, R., Silva, V. et al. (2006) Translocation of inhaled ultrafine manganese oxide particles to the central nervous system. Environ. Health Perspect., 114(8), 1172-1178.

8. Stepanyuk, S.M., Pokhodnya, I.K., Yavdoshchin, I.R. (2012) Study of morphology, chemical composition and dispersion of particles of Ts3A welding electrodes with different types of coatings. In: Proc. of $2^{\text {nd }}$ All-Ukrainian Sci.-Techn. Conf. of Junior Sci. and Students (Ukraine, Koblevo, 4-8 Sept. 2012).

9. Cena, L.G., Chisholm, W.P., Keane, M.J. et al. (2015) A field study on the respiratory deposition of the nano-sized fraction of mild and stainless steel welding fume metals. J. Occup. Environ. Hyg., 12(10), 721-728.

10. Demetska, O.V., Leonenko, O.B., Tkachenko, T.Yu. et al. (2012) Dynamics of concentration of ultradispersed particles in manual welding with electrodes. Ukr. Zhurnal z Medycyny Pratsi, 1, 3-7.

11. James, M., Antonini, J.M. (2003) Health effects of welding. Critical Rev. in Toxicology, 33(1), 61-103.

12. Antonini, J.M., Roberts, J.R., Stone, S. et al. (2011) Persistence of deposited metals in the lungs after stainless steel and mild steel welding fume inhalation in rats. Arch. Toxicol., 85(5), 487-498.

13. Antonini, J.M., Badding, M.A., Meighan, T.G. et al. (2014) Evaluation of the pulmonary toxicity of a fume generated from a nickel-, copper-based electrode to be used as a substitute in stainless steel welding. Environ. Health Insights, 15(8), $11-20$.

14. Pokhodnya, I.K., Suprun, S.A., Onoprienko, E.N. (1983) Occupational hygiene. Respubl. Mezhved. Sbornik Zdorovie, Issue $19,37-43$.

15. Antonini, J.M., Lawryk, N.J., Krishna Murthy, G.G. et al. (1999) Effect of welding fume solubility on lung macrophage viability and function in vitro. J. Toxicol. Environ. Health, 58, 343-363.

16. Maxild, J., Andersen, M., Kiel, P. et al. (1978) Mutagenicity of fume particles from metal arc welding on stainless steel in the salmonella/microsome test. Mutat. Res., 56, 235-243.

17. Baker, R.S.U., Arlauskas, A., Tandon, R.K. et al. (1986) Toxic and genotoxic action of electric arc welding fumes on cultured mammalian cells. J. Appl. Toxicol., 6, 357-362.

18. Biggart, N.W., Rinehart, R.R., Verfaille, J. (1987) Evidence for the presence of mutagenic compounds other than chromium in particles from mild steel welding. Mutat. Res., 180, 55-65.

19. Elias, Z., Poirot, O., Baruthio, F. et al. (1991) Role of solubilized chromium in the induction of morphological transformation of Syrian hamster embryo (SHE) cells by particulate chromium (VI) compounds. Carcinogenesis, 12, 1811-1816.

20. Hansen, K., Stern, R.M., Fletcher, A. et al. (1985) Nickel and chromium compounds and welding fumes in mammalian cell transformation bioassay in vitro. In: Biological effects and health hazards of welding fumes and gases, 305-310. Amsterdam: Elsevier Press.

21. Badding, M.A., Fix, N.R., Antonini, J.M. et al. (2014) A comparison of cytotoxicity and oxidative stress from welding fumes generated with a new nickel-, copper-based consumable versus mild and stainless steel-based welding in RAW 264.7 mouse macrophages. PLOS ONE, 9(6), 11-20. 